\title{
TIME MANAGEMENT AND DENTAL HYGIENE DURING THE ISOLATION PERIOD IN THE CONTEXT OF THE COVID-19 PANDEMIC
}

\author{
$\begin{array}{ll}\text { E.-S. INDREICA } & \\ & \text { A. NICOLAU }\end{array}$
}

\begin{abstract}
This study is an ascertaining one, its purpose being to find out if there is a relationship between time management and oral hygiene in the context of the COVID-19 pandemic, during the isolation period. We started from the presumption that people who stay at home, even if they have more free time, will pay special attention to dental hygiene only depending on their time management. The objectives of the study involve exploring the associations between three variables of the oral hygiene dimension and three variables of the time management dimension. The number of respondents was 260, aged between 18 and 82, both from urban areas (67.3\%) and from rural areas (32.7\%). The participants are predominantly female. To test the hypothesis, we developed and used a questionnaire that addressed issues related to oral hygiene and we adapted and used a time management questionnaire (Indreica, 2019). The obtained results confirmed the existence of an association between the two dimensions, the correlations between their variables being highly significant. The implications and limitations of the research are also summarized in this paper.
\end{abstract}

Key words: time management, oral hygiene, COVID-19.

\section{Introduction}

When we procrastinate some of the responsibilities of everyday life, the most common reason found empirically is time crisis. Following an opinion poll conducted during the course of Developmental Psychology (in 2019, having as topic of discussion the formation of hygiene skills in pre-schoolers), which was attended by 74 students (mostly female), the dominant answer to the question "do you wash your teeth every morning?" was "we don't even have time to eat in the morning, let alone to brush our teeth!" (62 respondents, representing 83.78\%). Then we asked ourselves: can neglecting dental hygiene be an effect of a real time crisis or of a poor time management? Here is a question to which we tried to find an answer in the context of the COVID-19 pandemic, during the period of isolation, a period in which the time crisis was no longer a major

\footnotetext{
${ }^{1}$ Transilvania University of Braşov, elena.indreica@unitbv.ro, corresponding author

2 Transilvania University of Braşov
} 
problem (if we were to consider only the gain of time that was spent, pre-isolation, in traffic).

Dental hygiene is a daily activity that aims to maintain not only the health of the teeth and the entire oral cavity, but it also is a starting point for the general health and well-being of the whole body. The latest scientific research demonstrates an interpolation between dental health, oral cavity diseases and systemic complications in several organs, involving the cardiovascular system and even neurodegenerative pathology. Some authors report that some rare pathologies such as Von Willebrand's disease, enteropathic acrodermatitis, sd. Chediak-Higashi, etc. have important correlations with oral health. Periodontal disease caused by poor dental hygiene can have serious systemic effects through the blood-borne spread of pathogenic bacteria throughout the body and the negative effect of inflammation (Poole \& Newman, 1971). Diabetes control is complicated for patients who also suffer from periodontal disease. Also, patients with diabetes and periodontal disease are simultaneously subject to complications of cardiovascular, renal and retinopathy diseases. Recently, the presence of bacteria responsible for periodontal disease has been reported present in the brain tissue of patients suffering from Alzheimer's disease (Cicciù, 2016; Dominy et al., 2019).

According to epidemiological data, dental and periodontal disease due to poor dental hygiene occurs among populations with low socio-economic status (Manski, 2014). Dental care is poorly funded, and the world has to make difficult financial choices when accessing dental care. Given that economic difficulties can adversely affect the quality of oral health and that, in turn, poor oral health can adversely affect overall health, it can be inferred that a citizen's socio-economic conditions have a short-term influence on solvable oral pathologies, and, in the long run, in addition to becoming chronic irreversible oral diseases, they also cause a deterioration of the individual's general health (Kaleddienè et al., 2008; Snow \& McNally, 2010; Žemaitienè et al., 2016).

It is important to mention that there is a strong psychological component, associated with the fear of patients in need of dental care (Bruno et al., 2018; Genc et al., 2018). Therefore, improvement of dental hygiene contributes to the prevention of diseases of the oral cavity and of the whole body, with favourable implications for society and for increasing the individuals' quality of life.

Fundamental research over the past 40 years have shown that plaque which builds up at the tooth / gum interface and on the teeth is the major cause of gingival inflammation and tooth decay. This led to the conclusion that the plaque needs to be removed from the teeth and gums to a level compatible with their health, mainly by brushing the teeth. This is the most important preventive and therapeutic procedure available to any individual. In no branch of medicine does the patient participate in controlling the disease as in this situation. Individuals need to be motivated, educated and trained in dental hygiene in dental practices as well as with other means. Important in performing a correct tooth brushing are the brushing technique and the brushing moments. Brushing should be performed at least twice a day, in the morning upon waking and in the evening before going to bed.

Regarding time management, our concerns in recent years (Indreica et al., 2011; Indreica, 2014; Indreica, 2016; Indreica, 2019) have provided answers to a number of 
questions, but have also generated others: why we invoke the fact that we don't have a 10 minutes period to serve 3 meals a day, but then we eat compulsively for about 30 minutes in the evening? Why don't we practice sports for 15 minutes a day, but turn on the TV for about 20 minutes zapping from one channel to another? Why don't we have 5 minutes to brush our teeth twice a day, but we look at the clothes in the wardrobe for more than 10 minutes wondering what to wear? Why don't we read 30 minutes from a book, but read messages or posts on social networks for over 60 minutes?... How could we do both? Basically, time management refers to ways of organizing activities so that you can cope optimally with the demands of both professional and private life (Unger et al., 2014; Knecht \& Freund, 2016).

To reduce stress at work, there are multiple studies that optimize time management (Yang, 2016; Alshaya et al., 2017) in order to obtain professional or school performance. Despite the abundance of research on time management (Pozdeeva, 2019), however, in our area of interest, investigations are rarer and, in general, of the ascertaining type (Nguyen \& Truong, 2020). Improving the quality of life focuses mainly on the time allocated to tasks necessary for the daily personal activities, which implicitly leads to the need for practical and easy to implement proposals. Recent concerns in the field of smartphone applications (Kim et al., 2019) support the development of a time management programme and make viable the idea of making available to anyone a tool to help them in this regard, without the need for a strict coordination of the programme by an educational counsellor - beneficial aspect (Indreica et al., 2011), but not feasible on a large scale.

\section{Objectives}

The search for practical and easy-to-implement solutions to improve the quality of life according to time management is the ideal we strive for. The present investigation, of an ascertaining type, is part of a complex project. Some of the studied aspects have already been published (Indreica, 2014; Indreica, 2016; Indreica, 2019), another part being in progress. We intend that, starting from the results obtained by approaching multiple facets of the rhythm of daily life, to develop and apply an individualized time management programme.

The aim of the present study is to find out whether there is a relationship between time management and oral hygiene in the context of the COVID-19 pandemic, during the isolation period.

We started from the presumption that people who stay at home, even if they have more free time, will pay special attention to the dental hygiene only depending on their time management. Hence the hypothesis that there is a relationship between dental hygiene and time management in conditions favourable to free time (the isolation period in the context of the COVID-19 pandemic). The objectives of the study involve exploring the associations between three variables of the oral hygiene dimension (complexity, frequency, and attitude) and three variables of the time management dimension (planning, monitoring, and efficiency). 


\section{Materials and Method}

To test the hypothesis, we developed and used a questionnaire that addressed issues related to dental hygiene - DHQ, and we adapted and used a time management questionnaire - TMQ (Indreica, 2019).

The first questionnaire (Annex 1) covers the dimension of dental hygiene and includes 10 items focused on three variables: complexity (use of materials and tools related to dental hygiene); frequency (number of brushings per day and time allocated to each brushing); attitude (priority given to dental hygiene in the daily routines). Each variable was measured by means of indicators (minimum 1, maximum 2), and each indicator was represented in the questionnaire by one or more items. The allocation of items according to the indicators related to each variable is shown in table 1 . The answers are presented on a scale from 1 (very rarely) to 5 (very often). The Alpha Cronbach coefficient is .76, which means that the test has a good internal consistency.

The second questionnaire (Annex 2) contains 24 items (with one item less than the 2019 version; item 19 was dropped as it was not relevant for the measured dimension; items that were not clearly stated were rephrased). The 24 items are focused on three variables of the time management dimension: activity planning, activity monitoring and activity efficiency. Each variable was measured by means of indicators (minimum 3, maximum 4) and each indicator was represented in the questionnaire by one or more items. The allocation of items according to the indicators related to each variable is shown in table 1 . The answers are presented on a scale from 1 (very rarely) to 5 (very often). The Alpha Cronbach's coefficient is .81, which means that the test has a good internal consistency.

Grouping items on the variable indicators

Table 1

\begin{tabular}{|c|c|c|c|c|}
\hline Dimensions & Variables & Indicators & Instrument & Items \\
\hline \multirow[t]{5}{*}{ dental hygiene } & \multirow[t]{2}{*}{ complexity } & use of materials & $\mathrm{DHQ}$ & $6 ; 7$ \\
\hline & & use of instruments & $\mathrm{DHQ}$ & $5 ; 8 ; 9 ; 10$ \\
\hline & \multirow[t]{2}{*}{ frequency } & brushings per day & $\mathrm{DHQ}$ & $1 ; 3$ \\
\hline & & time allotted to brushing & $\mathrm{DHQ}$ & $4 ;$ \\
\hline & attitude & prioritising activities & $\mathrm{DHQ}$ & 2 \\
\hline \multirow{10}{*}{$\begin{array}{l}\text { time } \\
\text { management }\end{array}$} & \multirow{4}{*}{$\begin{array}{l}\text { activity } \\
\text { planning }\end{array}$} & making a schedule & TMQ & 5,19 \\
\hline & & prioritising activities & TMQ & $1,2,4,9$ \\
\hline & & time distribution & TMQ & 6,12 \\
\hline & & clearly defined goals & TMQ & 10,11 \\
\hline & \multirow{3}{*}{$\begin{array}{l}\text { activity } \\
\text { monitoring }\end{array}$} & using a schedule & TMQ & 20 \\
\hline & & $\begin{array}{l}\text { observing the time allotted to each } \\
\text { activity }\end{array}$ & TMQ & $7,8,15,23$ \\
\hline & & redistributing time & TMQ & 13,16 \\
\hline & \multirow{3}{*}{$\begin{array}{l}\text { activity } \\
\text { efficiency }\end{array}$} & achieving the activities & TMQ & $3,21,22$ \\
\hline & & asking for support & TMQ & 14,24 \\
\hline & & making use of free slots of time & TMQ & 17,18 \\
\hline
\end{tabular}




\section{Participants}

The participants in this study were initially 280 in number, out of which only 20 were male. For the accuracy of data processing, we chose to process only the answers provided by the female group. Therefore, we had $\mathrm{N}=260$, only female respondents. The average age of the group is 33.5 (standard deviation of 12.5), the minimum value being 18 years old and the maximum, 82 years old. The area of origin of the respondents was both urban (175 respondents, representing 67.3\%) and rural (85 respondents, representing $32.7 \%)$. Out of the 260 respondents, 54 are smokers (20.8\%) and 206 nonsmokers (79.2\%).

The distribution of the questionnaires was done exclusively online. The questionnaires were written in Google Forms and distributed on social networks and 280 people answered, all the questionnaires being valid (due to the mandatory setting of providing the answer to each item). As the number of male respondents was 20 , we excluded their answers from the database, processing only the answers of the female group $N=260$. Participation in the study was voluntary, the online environment giving them the comfort of answering whenever they wanted, without having a time limit. Data collection was performed over five days, with access to the questionnaires being closed towards the end of the fifth day after it was found that the intensity of viewing and completing of the questionnaires decreased to a frequency of one person every three hours.

\section{Results}

From the analysis of the data obtained from the tested group, it results that the planning of activities has a positive, significant correlation with: the complexity of performing dental hygiene $(r=.231, p<.01)$, the frequency of brushing teeth $(r=.303, p$ $<.01)$ and the attitude towards dental hygiene as a priority in daily activities ( $r=.165, p$ $<.01)$, as it can be seen in Table 2. The three variables of the dental hygiene dimension (DH) increase with the planning of activities, which means that drawing up a schedule, organizing activities according to priorities, distributing time slots to specific activities and setting clearly defined objectives emphasize the concern for a hygienic-dental schedule and an adaptation of the daily schedule in order to increase the quality of life.

Table 2

Pearson correlation coefficients between the dimensions of TM and DH

\begin{tabular}{|l|l|l|l|r|r|r|}
\hline & 1 & 2 & 3 & 4 & 5 & 6 \\
\hline activity planning (1) & & $.631^{* *}$ & $.582^{* *}$ & $.231^{* *}$ & $.303^{* *}$ & $.165^{* *}$ \\
\hline activity monitoring (2) & & & $-534^{* *}$ & $.294^{* *}$ & $.350^{* *}$ & $.288^{* *}$ \\
\hline activity efficiency (3) & & & & $.137^{*}$ & $.264^{* *}$ & $.149^{*}$ \\
\hline Complexity (4) & & & & & $.500^{* *}$ & $.346^{* *}$ \\
\hline D H frequency (5) & & & & & & $.529^{* *}$ \\
\hline D H attitude (6) & & & & & & - \\
\hline
\end{tabular}

$$
{ }^{*} \mathrm{p}<.05 ; * * \mathrm{p}<.01 ; \mathrm{N}=260
$$


Regarding the monitoring of activities, the results are similar, these correlating with: the complexity of performing dental hygiene $(r=.294, p<.01)$, the frequency of teeth brushing $(r=.350, p<.01)$ and the attitude towards dental hygiene as a priority in daily activities $(r=.288, p<.01)$, as it can be seen in table 2 . The three variables of the dimension of dental hygiene (DH) increase with the monitoring of activities, as seen in table 2. This highlights the fact that it is very important to use a schedule, to respect the time allocated to activities in the phase of their organization and to redistribute the remaining time if some of the scheduled activities have been carried out efficiently in a shorter time than allotted.

Significant correlations were also obtained between the efficiency of activities and the three variables related to the dental hygiene dimension: the complexity of performing dental hygiene $(r=.137, p<.05)$, the frequency of brushing teeth $(r=.264, p<.01)$ and the attitude towards dental hygiene as a priority in daily activities $(r=.149, p<.05)$, as it can be seen in Table 2 .

In addition to the factual data regarding age, area of origin and the smoker / nonsmoker status, we also introduced an item through which participants were requested to indicate dental problems on a scale from 1 (very few) to 5 (very many). From the data analysis, it was found that there is a significant, negative correlation between dental problems and the attitude towards dental hygiene $(r=-.151, p<.05)$ - table 3 . We can say that dental health problems decrease with increase of the interest for dental hygiene (indicator for the variable attitude towards dental hygiene). We expected this correlation between dental problems and the attitude towards dental hygiene to be strongly significant, but the weak correlation can be explained either by the too general expression of the item or by different perceptions of the patient and doctor towards the dental problems (e.g., a tooth filling is no longer a problem for the patient and he can choose level 1 , while - from a medical point of view - a tooth filling remains a problem of at least level 3 , requiring regular treatment and control).

Table 3

Pearson correlation coefficients - dental problems and dimensions of the TM and DH

\begin{tabular}{|l|r|r|r|r|r|r|r|}
\hline & $\begin{array}{c}\text { activity } \\
\text { planning }\end{array}$ & $\begin{array}{c}\text { activity } \\
\text { monitoring }\end{array}$ & $\begin{array}{c}\text { activity } \\
\text { efficiency }\end{array}$ & complexity & $\begin{array}{c}\text { D H } \\
\text { frequency }\end{array}$ & $\begin{array}{c}\text { D H } \\
\text { attitude }\end{array}$ & $\begin{array}{c}\text { activity } \\
\text { planning }\end{array}$ \\
\hline $\begin{array}{l}\text { dental } \\
\text { problems }\end{array}$ & - & .098 & .054 & .082 & .059 & .004 & $-.151^{*}$ \\
\hline
\end{tabular}

The results of the $t$ test do not indicate statistically significant differences between respondents from urban areas and those from rural areas in any of the variables of the two dimensions - time management and oral hygiene, as it can be seen in Table 4.

For the analysis of the bifactorial variance, the variable attitude towards dental hygiene and area of origin and smoker / non-smoker status were taken into account. The data from Table 5 gives us information about the Levene test, which verifies the similarity of the variants. Since the significance of this test is $p=0.447$ the variances are similar. 
Table 4

Descriptive statistics and values of $t$ - the variables of the TM and DH dimensions, according to the area of origin

\begin{tabular}{|c|c|c|c|c|c|c|}
\hline Dimension & Area & $\mathrm{N}$ & Mean & Std. Deviation & Std. Error Mean & $\mathrm{t}$ \\
\hline \multirow[t]{2}{*}{ activity planning } & urban & 175 & 36.48 & 5.680 & .429 & -1.083 \\
\hline & rural & 85 & 37.29 & 5.705 & .619 & \\
\hline \multirow[t]{2}{*}{ activity monitoring } & urban & 175 & 22.94 & 3.695 & .279 & -.981 \\
\hline & rural & 85 & 23.42 & 3.733 & .405 & \\
\hline \multirow[t]{2}{*}{ activity efficiency } & urban & 175 & 24.58 & 3.794 & .287 & -1.878 \\
\hline & rural & 85 & 25.56 & 4.333 & .470 & \\
\hline \multirow[t]{2}{*}{ complexity } & urban & 175 & 16.82 & 5.023 & .380 & -1.010 \\
\hline & rural & 85 & 17.49 & 5.030 & .546 & \\
\hline \multirow[t]{2}{*}{ D H frequency } & urban & 175 & 9.53 & 2.789 & .211 & -1.855 \\
\hline & rural & 85 & 10.21 & 2.816 & .305 & \\
\hline \multirow[t]{2}{*}{ D H attitude } & urban & 175 & 4.22 & .994 & .075 & -1.579 \\
\hline & rural & 85 & 4.41 & .791 & .086 & \\
\hline
\end{tabular}

Levene's Test of Equality of Error Variance

Table 5

\begin{tabular}{|c|c|c|c|c|}
\hline & $\mathrm{F}$ & df1 & df2 & Sig. \\
\hline area of origin + smoker / non-smoker & .890 & 3 & 256 & .447 \\
\hline
\end{tabular}

Design: Intercept + area of origin + smoking + area of origin $*$ smoking

For the variable area of origin, $F$ value it is not significant at the threshold of $p=0.290$ (Table 6), which means that there is no significant interaction between the respondents' area of origin and the attitude towards dental hygiene. For the variable smoker / nonsmoker status, the ratio $F(0.394)$, it is not significant at the threshold of $p=0.531$ (Table $6)$, which means that there is no significant interaction between the smoker / nonsmoker status and the attitude towards dental hygiene.

Table 6

The analysis of the bifactorial variance $-D H$ attitude

\begin{tabular}{|l|r|r|r|r|r|}
\hline Dependent Variable: attitude towards dental hygiene \\
\hline Source & $\begin{array}{c}\text { Type III Sum of } \\
\text { Squares }\end{array}$ & \multicolumn{1}{c|}{$\begin{array}{l}\text { Mean } \\
\text { Square }\end{array}$} & \multicolumn{1}{c|}{$\mathrm{F}$} & \multicolumn{1}{c|}{ Sig. } \\
\hline Corrected Model & $2.910^{\mathrm{a}}$ & 3 & .970 & 1.111 & .345 \\
\hline Intercept & 1900.799 & 1 & 1900.799 & 2176.288 & .000 \\
\hline area of origin & .984 & 1 & .984 & 1.126 & .290 \\
\hline Smoker / non-smoker & .344 & 1 & .344 & .394 & .531 \\
\hline area of origin * smoking & .020 & 1 & .020 & .022 & .881 \\
\hline Error & 223.594 & 256 & .873 & & \\
\hline Total & 4991.000 & 260 & & & \\
\hline Corrected Total & 226.504 & 259 & & & \\
\hline
\end{tabular}

a. R Squared $=.013$ (Adjusted R Squared $=.001$ ) 
The same conclusion can be drawn for the interactions between the two variables (area of origin and smoking) for which the $F$ value is not significant at the threshold of $p$ $=0.881$. In conclusion, the bifactorial analysis shows that both in the case of the area of origin and the status of smoker / non-smoker, and the interaction between the area of origin and smoking, there are no significant effects that influence the attitude towards dental hygiene.

\section{Discussion}

Based on the results obtained from this study, it can be stated that there is an association between time management and dental hygiene regardless of context, the variables of the two dimensions correlating significantly from the statistical point of view. Increasing the planning of activities according to clearly defined objectives and priorities, monitoring the planned time and making the activities more efficient lead implicitly to a complex and efficient dental hygiene.

If between those who plan the activities ( 241 respondents - $92.6 \%$ - cumulative percentage for often and very often) and those who perform important activities every day (204 respondents - $78.4 \%$ - cumulative percentage for often and very ofte ), there is only a difference of $14.2 \%$ percent, the difference increases to $39.6 \%$ when it comes to activities from the private life - 138 respondents, for example, brush their teeth 3 times a day (53\% - cumulated for often and very often). This can have two causes: either 1 . this type of activities, minor but necessary to increase the quality of life, are not included in the list of planned activities; or 2. they are included in the list, but people do not monitor the time allocated to them ( 44 respondents - $16.9 \%$ - allocate time to these activities when planning them) and consumed by them ( 7 respondents $-2.6 \%$ - monitor the time spent), this kind of activities being dropped when one reaches time deficit. Planning and monitoring where time is actually spent is not enough if we do not take into account the efficiency of activities - we refer here only to the time spent daily on social networks. Taking advantage of downtime or calling for support (qualified or not, depending on the situation) would be two suggestions to ensure success in optimizing time management.

Allotting time for certain predefined activities does not, however, implicitly lead to its use in this regard. Monitoring activities (using the schedule, observing the time allocated to activities and redistributing the time left after make an activity more efficient) is an important variable in time management and, as is clearly results from data processing, correlates strongly and positively with all three variables of the dental hygiene dimension. The analysis of the data shows that, although $136(52.3 \%)$ of the respondents very often and 105 (40.3\%) often establish an order in which to carry out their activities, the percentages decrease when noting the time spent on each activity. $7(2.6 \%)$ very often and $15(5.7 \%)$ often, and at the end of the day only $54(20.7 \%)$ know exactly what time was spent on.

This means that, in order to comply with the parameters of an optimal time management (allocated, consumed and redistributed), it is not enough just to compile a list of activities in order of their priority, but also to use time management techniques 
(only 20 respondents $-7,6 \%$ - use such techniques).

The data of this ascertaining study show that the people who practice an efficient time management pay special attention to the dental hygiene, both in terms of frequency and quality (tools and materials used).

The study did not capture numerically the time allocated to travel, before isolation, to / from school / work in order to be taken into account in a concrete way; also, there were no items referring to dental hygiene before isolation - these can be considered limits of research. We can pay special attention in subsequent research to the reasons behind the spending time, depending on the activities related to the pace of daily life.

\section{References}

Alshaya, H. M., Roomi, M. A., Alzayer, M. A., Alonze, S. K., \& Alshaalan, R. F. (2017). Is time management related to better academic performance and perceived academic satisfaction among medical students? A cross-sectional survey in Saudi Arabia. International Journal of Advanced Research, 5, 2205-2213.

Bruno A., Muscatello, M. R. A., Pandolfo, G., Ciura, G., Quattrone, D., Scimeca, G., Mento, C., \& Zoccali, R. A. (2018). Does Personality Matter? Temperament and Character Dimensions in Panic Subtypes. Arch. Neuropsychiatry, 55, 325-329. doi: 10.29399/npa.20576

Cicciù, M. (2016). Neurodegenerative disorders and periodontal disease: Is there a logical connection? Neuroepidemiology, 47, 94-95. doi: 10.1159/000449517

Dominy, S. S., Lynch, C., Ermini, F., Benedyk, M., Marczyk, A., Konradi, A., Nguyen, M., Haditsch, U., Raha, D., \& Griffin C. (2019). Porphyromonas gingivalis in Alzheimer's disease brains: Evidence for disease causation and treatment with small-molecule inhibitors. Sciences Advances, 5:eaau3333. doi: 10.1126/sciadv.aau3333

Genc, T., Duruel, O., Kutlu, H. B., Dursun, E., Karabulut, E., \& Tozum, T. F. (2018). Evaluation of anatomical structures and variations in the maxilla and the mandible before dental implant treatment. Dental and Medical Problems, 55, 233-240. doi: $10.17219 / \mathrm{dmp} / 94303$

Indreica, E. S., Cazan, A. M., \& Truta, C. (2011). Effects of learning styles and time management on academic achievement. Procedia Social and Behavioral Sciences, 30, 1096-1102.

Indreica, E.-S. (2014). E-learning platform: advantages and disadvantages on time management. The International Scientific Conference "Elearning and Software for Education", Bucureşti.

Indreica, E., \& Cazan, A. (2016). Time management, constellation of interests and students' attitude towards e-learning platform. Educatia 21, (14), 32-38. Retrieved from https://search.proquest.com/docview/1852734781? accountid=7257.

Indreica, E.-S. (2019). Time management and healthy food - Ascertaining study in Bulletin of Transilvania University of Brasov, Series VII: Social Sciences and Law, 2, 229236. 
Kalèdienè, R., Starkuvienè, S., \& Petrauskienè, J. (2008). Inequalities in life expectancy by education and socioeconomic transition in Lithuania. Medicina, 44, 713-728. doi: 10.3390/medicina44090092.

Knecht, M., \& Freund, A. (2016). Boundary management: A time-sampling study on managing work and private life in middle adulthood. Research in Human Development, 13(4), 297-311. doi: 10.1080/15427609.2016.1234307

Manski, R. J., Moeller, J. F., Chen, H., Schimmel, J., St. Clair, P. A., \& Pepper, J. V. (2014). Dental usage under changing economic conditions. Journal of Public Health Dentistry, 74, 1-12. doi: 10.1111/j.1752-7325.2012.00370.x

Nguyen, V., \& Truong, N. (2020). The role of time management skills in fulfilling assignments of research methodology subject of senior students - a case study at Tra Vinh university. The Scientific Journal of Tra Vinh University, 1(37), 69-77. doi: 10.35382/18594816.1.37.2020.378

Poole, D. F., \& Newman, H. N. (1971). Dental plaque and oral health. Nature, 234, 329331. doi: $10.1038 / 234329 a 0$

Pozdeeva, E. S. (2019). Students' time management in higher education. Retrieved from https://www.researchgate.net/profile/Ekaterina_Pozdeeva3/publication/334093407S

Snow, P., \& McNally, M. E. (2010). Examining the implications of dental treatment costs for low-income families. Journal of Canadian Dental Association, 76, a28. Retrieved from https://pubmed.ncbi.nlm.nih.gov/20388313/

Unger, D., Niessen, C., Sonnentag, S., \& Neff, A. (2014). A question of time: Daily time allocation between work and private life. Journal of Occupational and Organizational Psychology, 87, 158-176.

Yang, H. (2016). Impact of time management for IT services management. Procedia Computer Science, 91, 700-706. https://doi.org/10.1016/j.procs.2016.07.173

Žemaitienė M., Grigalauskienè, R., Vasiliauskienè, I., Saldūnaitė, K., Razmienè, J., \& Slabšinskienè, E. (2016). Prevalence and severity of dental caries among 18-year-old Lithuanian adolescents. Medicina, 52, 54-60. doi: 10.1016/j.medici.2016.01.006 
Annex 1: Dental hygiene questionnaire

\begin{tabular}{|c|c|c|c|c|c|c|}
\hline \multirow[t]{2}{*}{ No } & \multirow[t]{2}{*}{ ITEMS } & \multicolumn{5}{|c|}{ SCALE* } \\
\hline & & 1 & 2 & 3 & 4 & 5 \\
\hline 1. & I always brush my teeth at least three times a day & & & & & \\
\hline 2. & Brushing my teeth is always a priority & & & & & \\
\hline 3. & I always brush my teeth after eating & & & & & \\
\hline 4. & Brushing always takes me at least three minutes & & & & & \\
\hline 5. & I floss before using my toothbrush & & & & & \\
\hline 6. & Mouthwash is part of my toothbrushing ritual & & & & & \\
\hline 7. & I've been using more toothpaste lately & & & & & \\
\hline 8. & I pay special attention to cleaning my tongue, too when brushing my teeth & & & & & \\
\hline 9. & I use interdental brushes every time I brush my teeth & & & & & \\
\hline 10. & I use the mouth shower after every toothbrush & & & & & \\
\hline
\end{tabular}

Annex 2: Time Management Questionnaire

\begin{tabular}{|c|c|c|c|c|c|c|}
\hline \multirow[t]{2}{*}{ No. } & \multirow[t]{2}{*}{ ITEMS } & \multicolumn{5}{|c|}{ SCALE* } \\
\hline & & 1 & 2 & 3 & 4 & 5 \\
\hline 1 & $\begin{array}{l}\text { I establish an order in which to carry out my activities, depending on } \\
\text { my priorities. }\end{array}$ & & & & & \\
\hline 2 & $\begin{array}{l}\text { I make a list with the order in which I carry out my activities, according } \\
\text { to my priorities. }\end{array}$ & & & & & \\
\hline 3 & To be as efficient as possible, I group similar activities. & & & & & \\
\hline 4 & I carry out my activities in the order of priorities. & & & & & \\
\hline 5 & I always plan time for recreation or rest. & & & & & \\
\hline+6 & I set a working time for each activity. & & & & & \\
\hline 7 & I write down the time spent on each activity. & & & & & \\
\hline 8 & At the end of the day, I know exactly where my time has gone. & & & & & \\
\hline 9 & I achieve the important activities every day & & & & & \\
\hline 10 & I try not to be distracted from my activity. & & & & & \\
\hline 11 & I focus on all the activities I do, not just on the ones I enjoy. & & & & & \\
\hline 12 & $\begin{array}{l}\text { I allocate, in my schedule, enough time for lunch / coffee / relaxation / } \\
\text { conversation breaks. }\end{array}$ & & & & & \\
\hline 13 & I do not waste time with activities that I find useless. & & & & & \\
\hline 14 & I call for collaboration when I have to achieve a more difficult goal. & & & & & \\
\hline 15 & I always manage to finish what I started. & & & & & \\
\hline 16 & $\begin{array}{l}\text { I start the activity immediately and I don't like to procrastinate, even if } \\
\text { it's something unpleasant. }\end{array}$ & & & & & \\
\hline 16 & $\begin{array}{l}\text { I exclude from my schedule activities that only consume time, without } \\
\text { any efficiency. }\end{array}$ & & & & & \\
\hline 17 & I avoid prolonged phone conversations. & & & & & \\
\hline 18 & I only answer the phone if necessary. & & & & & \\
\hline 19 & I put into practice what I have decided to do. & & & & & \\
\hline
\end{tabular}




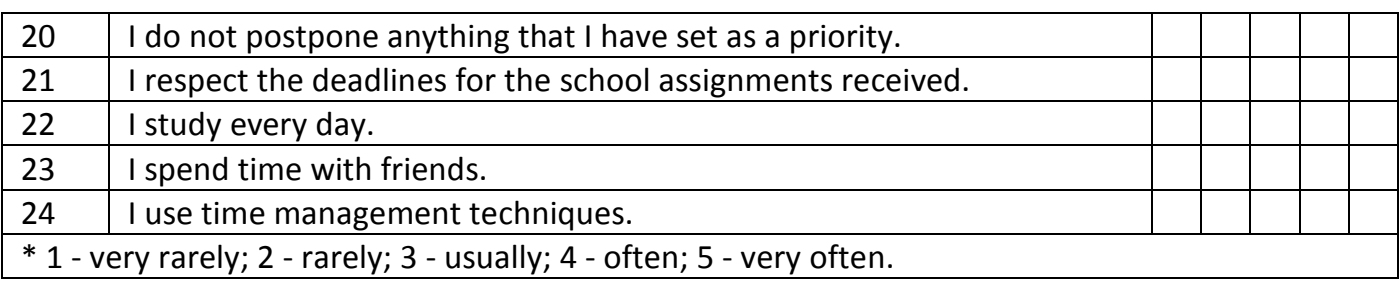

